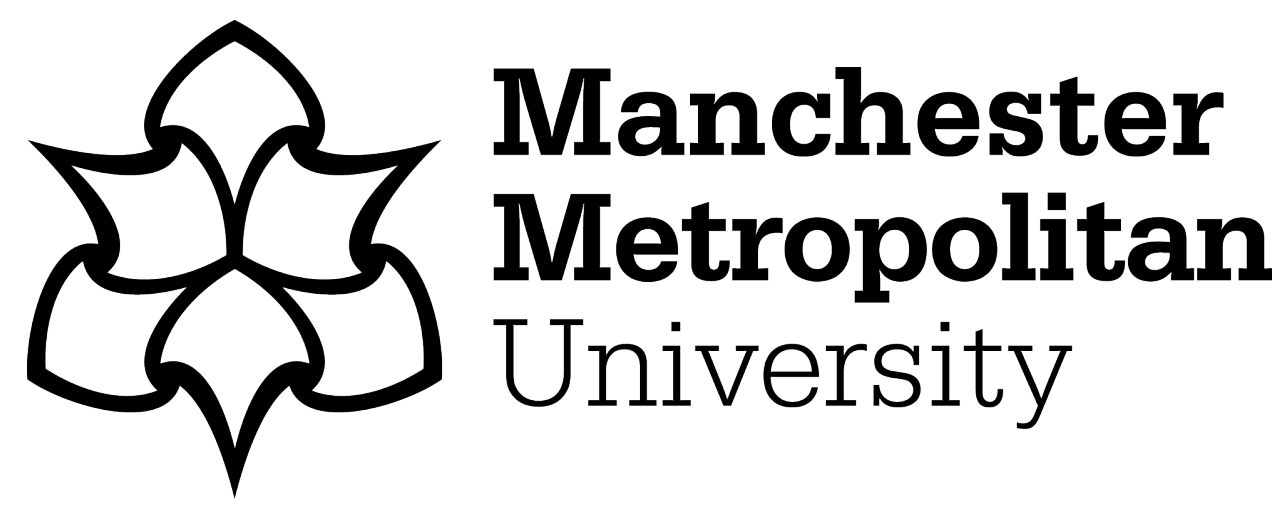

Archer, Dawn ORCID logoORCID: https://orcid.org/0000-0002-4547-6518, Jagodziński, Piotr and Jagodziński, Rebecca (2021) Activity Types and Genres. In: Cambridge Handbook of Sociopragmatics. Cambridge Handbooks in Language and Linguistics . Cambridge University Press, pp. 206-226. ISBN 9781108954105

Downloaded from: https://e-space.mmu.ac.uk/625106/

Version: Accepted Version

Publisher: Cambridge University Press

DOI: https://doi.org/10.1017/9781108954105.012

Please cite the published version 


\title{
Activity Types and Genres
}

\author{
Dawn Archer, P. Jagodziński and R. Jagodziński \\ Manchester Metropolitan University
}

\begin{abstract}
This chapter critically compares how the concepts of activity type and genre tend to be used within the field of pragmatics. Both concepts are broadly concerned with the way in which we categorize our experiences, and develop thereby expectations about communicative behaviour within a given context. In spite of these similarities, they have very different conceptual histories. Activity types were introduced into pragmatics by Levinson (1979), having been inspired by Wittgenstein's (1958) notion of language games. Genres can be traced back to ancient Greek literature, and have since been applied within multiple disciplines, including art and art criticism, literary studies, rhetoric, sociology, linguistics and, more specifically, pragmatics (Bazerman, 1997; Mayes, 2003). The focus of the chapter is on mapping the development and usage of these terms within the pragmatics (or a concomitant) discipline. We also comment upon concepts that seem to share "a considerable family resemblance" (Linell, 2010: 42) with activity types and/or genres. They include footing, frames (and framing), speech events, speech activities, schemas, scripts, and prototypes.
\end{abstract}

\section{Introduction}

The concepts of activity type and, to a lesser extent, genre have proven useful for pragmaticians when seeking both to explain the extent to which context determines language use and the way in which interactants categorize their experiences, thereby developing expectations about their communicative behaviour within a given context (Tannen, 1993; Mayes, 2003). As will become evident, both concepts - but especially genre - are used quite extensively in other disciplines too (see Section 2.2). Sections 2-2.4 thus explore:

- Their different conceptual origins, and how they have been drawn upon within pragmatics (and related fields) since their introduction.

- Their similarities and differences with respect to one another.

- Their similarities and differences with respect to other concepts drawn upon by pragmaticians, for example, footing, frames (or framing), speech events, speech activities, schemas, scripts, and prototypes (Gumperz 1982: 166-7; Goffman 1981: 128; Tannen 1993:3; Tannen and Wallat 1993: 76; Mayes, 2003: 30-4).

Sections 3-3.2 then go on to describe a case study relating to the interview activity type (drawing upon Culpeper and McIntyre, 2010), and a case study relating to the genre of biographical data statements (drawing upon Tardy and Swales, 2014), following which promising areas for future research are identified (in Section 4).

\section{Key concepts and theories}

In the following sections, we first provide a working definition of the concepts of activity type and genre, outline their respective origins, and explore how they are drawn upon in the field of pragmatics as well as other (related) disciplines (see Sections 2.1 and 2.2). We then assess their similarities and differences both with respect to each other (see 2.3) and also related concepts (see 2.4). 


\subsection{The concept of activity type, its origins, and use in pragmatics}

Stephen Levinson is usually credited with introducing the concept of activity type into pragmatics. ${ }^{1}$ Inspired by Wittgenstein (1958), Levinson ([1979] 1992) sought to highlight that understanding the meaning of utterances requires us to also have an understanding of the activity within which the utterances occur. This assumes such activities are 'goal defined' as well as culturally recognisable, such that they place 'constraints on participants', especially in respect to what kinds of contributions are allowable (Levinson, 1992: 69). They are also 'bounded' in time in some way. ${ }^{2}$ It should be noted from the outset, however, that talk was not an essential criterion of every activity type, as far as Levinson was concerned. He noted additional ways in which distinct activity types might differ too. They might involve a single participant, such as a homework task, or several participants, such as a dinner party. They might be heavily scripted, such as a Roman Mass, or largely unscripted, such as a chance meeting on the street. They might be formal, such as a city council meeting, or informal, such as small talk between friends.

Some of the extant pragmatics studies that explore activity types also develop their understanding of the concept itself. Clark (1996) provides one such example. He argued that activity types can exhibit differences with respect to their cooperative traits and governance traits (i.e., how cooperative or egalitarian particular activity types are). He explains how they can 'range from cooperative activities like buying groceries to adversarial or competitive activities like playing tennis or cross-examining witnesses in court' (Clark, 1996: 31), for example. He further notes how a participant (A) might play a dominant role within a given activity type, whereby they do something 'to or for B', as in the case of lecturing, or how participants might have roughly equal roles, akin to A and B doing something together, as in the case of chess playing (Clark, 1996: 31). In a more recent study, Culpeper and McIntyre (2010) have argued that - and go on to demonstrate how - activity types (such as job interviews) can be both context-dependent and context-creating. They thus operationalise what Levinson ([1979] 1992) had only alluded to with respect to the 'inside out' view of the context being shaped by participants as well as the more frequently cited 'outside in' view of context determining language use, when it comes to activity types. Culpeper and McIntyre also emphasise another point to which Levinson alluded: how the activity type concept constitutes an indispensable bridge or the meso-level between the micro and the macro level of analysis, thereby 'rescuing' Grice's (1975) Cooperative Principle. ${ }^{3}$ We describe Culpeper and McIntyre's study in more detail in Section 3.1 (see also Section 2.3).

\subsection{The concept of genre, its origins, and use in pragmatics}

According to Martin (1985: 248), a genre 'is how things get done, when language' or another medium 'is used to accomplish them'. Martin (1984: 24) also delineates the concept based on

\footnotetext{
${ }^{1}$ But note also the similarity with some of Allwood's (1976) early work exploring Linguistic Communication as Action and Cooperation.

${ }^{2}$ One of the paradigm examples of an activity type, offered by Levinson (1979: 368), is that of teaching. Given the mention of "task in a workshop" as another paradigm example, amongst a list (job interview, jural interrogation, football game, dinner party) all of which are also bounded in time, we are assuming that Levinson had a bounded "episode" of teaching in mind, when he mentions the latter (cf. teaching as an ongoing process, and also Gumperz 1982).

${ }^{3}$ See also Mooney's (2004: 903) argument for the recontextualization of Grice's Cooperative Principle with Levinson's activity type, in the belief that "[i]t contextualizes the maxims and allows a clearer and more relevant construal of contributions".
} 
its characteristics, likening genre to 'a staged, goal-oriented, purposeful activity' or practice involving 'members of [the specified] culture'. The similarities to the concept of activity type are immediately apparent, and will be discussed in more detail in Section 2.3 (following). Suffice it to say, both concepts are broadly concerned with the way in which we categorize our experiences, and develop thereby expectations about communicative behaviour within a given context. There are important differences too, occasioned in part by their different origins: contra activity type, the origins of genre are not associated with one scholar, for example. This may help to explain (i) why it can be difficult to delineate genre as succinctly as we might activity type (see Section 2.1, above) and (ii) why genre tends to be described in terms of other concepts in consequence. Some of these concepts (frame, prototype, style) are noted below. These and other terms (domains, episodes, schemata, scripts, speech events) are also discussed in some detail in Sections 2.3 and especially 2.4.

Genre has a particularly long history when it comes to literary studies, as it can trace its roots back to ancient Greek literature, where it was used to distinguish poetry, prose and performance. Today, the concept is drawn upon by not only literary theorists (Bawarshi and Reiff 2010) but also art historians (see, e.g., Belton, 1996), musical theorists (see, e.g., van der Merwe, 1989) and linguists. Within linguistics, it has been particularly associated with the "Sydney School" of Systemic Functional Grammar (SFG) since the 1980s, thanks to researchers such as J.R. Martin, Frances Christie, Bill Cope, Mary Kalantzis, Gunther Kress and Brain Paltridge. Paltridge (1997) has linked SFG with prototype theory, for example, to allow for 'text membership within genres' to be defined 'on the basis of how closely their structural and linguistic patterns relate to' a given genre's prototype (Bawarshi and Reiff 2010: 39). As Barwarshi and Reiff (ibid.) explain, 'the relation between texts and genres is not simply based on features internal to both', but on what, from Paltridge's (1997: 62) perspective, equate to learned, conceptual relations between 'memory, context and frames'. Prototypes, in this case, are thus understood to provide a means of selecting, organizing and interpreting - with the aim of differentiating between - genres (see, for example, Lee, 2001). Several historical linguists and corpus linguists have also sought to provide a means of categorising genres, most notably Hans-Jürgen Diller and Douglas Biber. In his earlier work, for example, Biber (1988) was interested in the extent of linguistic variation within genres, which he measured along different dimensions: 'narrative versus non-narrative,' 'non-impersonal versus impersonal style,' and 'situation dependent versus elaborated reference'. The methods of both Biber and Paltridge have since been picked up by (and thus influenced) researchers interested in the study of English for Specific Purposes (ESP). As such, ESP researchers (many of whom are associated with the "North American" approach to genre studies) can also trace the use of genre analysis within their linguistic (sub)field to the 1980s. Particularly influential, here, is the work of John Swales (1990). As Tardy and Swales (2014: 166) note, Swales argued (following Miller, 1984) that:

[...] genres have a communicative purpose, which may in fact serve as the key characteristic for placing discourses into generic categories. In addition genres are socially situated. As a rhetorical category of discourse, genre cannot be distinct from social context. Genres arise within social contexts, [and] carried out for social purposes ranging from the relatively simple (e.g., creating a list of items to buy at a grocery store) to the more complex (e.g., outlining the terms of a business transaction). By virtue of their social situatedness, genres are necessarily dynamic, always changing (authors' italics). 
The above, and Tardy and Swales' (2014: 167) observation that 'genres both shape and are shaped by the communities and contexts in which they exist' (authors' italics), is where the overlap between genre and activity type is at its most evident (cf. Section 2.1; see also Section 2.3). For example, all of the linguistic approaches mentioned to date share 'the view that linguistic features' associated with a particular genre are always 'connected to social context and function' (Bawarshi and Reiff, 2010: 42) in some way. Those actions 'embody goals, actions' and 'activities' that are 'repeatedly required in similar situations', moreover, thereby explaining why genres (like activity types) are recognisable to users (Tardy and Swales, 2014: 167). Interestingly, genres are argued to embody 'histories and politics' too (Tardy and Swales, 2014: 167), which potentially sets them apart from activity types (see Section 2.3). This political characteristic helps to explain, in addition, why a growing number of researchers are opting to combine genre analysis with critical discourse analysis. Bhatia (2008) has even outlined a framework for a critical genre analytic approach, which brings together 'an analysis of text, genre, professional practice, and professional culture', by integrating 'what he calls 'text-internal features' (e.g., lexicogrammatical features, rhetorical moves) with 'text-external features' (e.g., institutional discourses, actions, and voices)' (Tardy and Swales, 2014: 173).

Given genre is so intimately interwoven with context, it is somewhat surprising that the term is not more widely used within pragmatics than it is currently. What has kept genre and activity type apart historically, according to Tardy and Swales (2014: 165), is not only their respective origins (as noted above), but also their particular (sub-)disciplinary origins and the previous foci of these (sub-)disciplines. For example, genre analysis (as a form of discourse analysis) often traces its roots to literary studies via anthropology and folklore studies. It has thus prioritised written texts historically. Pragmatics, in contrast, traces its origins to the work of ordinary language philosophers, and has often focussed on spoken data (typically, on a smaller scale). Over the past two decades, however, 'genre analysts have become increasingly interested in characterizing spoken genres, while pragmatists have additionally turned their attention to written texts and longer spoken utterances, especially when those texts have explicitly persuasive motivations' (Tardy and Swales, 2014: 165). Tardy and Swales' (2014) study provides us with one example of a pragmatics study which has used genre analysis as an important analytical tool, and will thus be discussed in more detail in Section 3.2.

\subsection{Activity type and genre: similarities and differences with each other}

Linell (1998: 239) has suggested that, because activity type and genre overlap conceptually in several ways, teasing them apart is essentially 'a matter of definition'. As noted in Section 2.2 (above), this is not a particularly easy endeavour. Indeed, linguists have suggested that both tend to be somewhat "fuzzy" concepts in practice (Levinson, 1979: 368; Włodarczyk, 2016: 47). Our starting point, then, will be the key points of convergence to have emerged reasonably consistently in the extant literature, namely:

(1) the socio-cultural ratification of (language use within) communicative activities

(2) the cognitive organisation of human experience, and

(3) act-activity co-construction.

In relation to (1), we may note that both activity type and genre are typically understood within pragmatics as having sociocultural underpinnings (Linell, 1999; Linell and Thunqvist, 2003). Levinson's activity type, for instance, describes communicative activities that are both 'socially constituted' and 'culturally recognizable' (1979: 368). Indeed, Levinson's concluding remarks in his original paper on activity types describe the notion by the name, social episodes (1979: 393; see also Forgas, 1979). He also draws upon the ethnography of speaking, and more 
specifically the work of Hymes (1962), stating that there are 'culturally-specific' language rules in operation when it comes to particular activity types:

...having a grasp of [activity-specific rules] will play an important role in the reception side of communicative competence, the ability to understand what one hears. And because these activity-specific rules are more culturally-specific than other sorts, they are likely to play a large role in cross-cultural or inter-ethnic miscommunications (Levinson 1979: 393)

Comparably, genre has been utilised both within and outside of pragmatics to investigate 'the relationship between language, social structure, and culture' (Mayes, 2003: 18; see also Luckmann, 1992). Whether and to what extent culture is foregrounded over and above social structure (or vice versa) may vary from scholar to scholar. As Włodarczyk (2016: 47) notes, for instance, some researchers within historical pragmatics see genre as predominantly cultural (Claridge, 2012), while others approach it from more of a social perspective (see, for example, Hoey, 2001). Broadly speaking, both notions therefore attempt to describe how language use is shaped by the wider sociocultural landscape in which activities are situated. That is to say, social actors need not "spontaneously" select communicative behaviours ab novo. Rather, they may (at least partly) rely upon existing patterns - patterns which are drawn from, and ratified by, the discourse community and/or the culture at large - as appropriate ways to speak and behave within a given activity (Luckmann, 1992: 244; see also Levinson, 1979: 370). In regard to (2), the concepts of genre and activity type delineate contextual resources not only in terms of social structure and culture, but also in terms of cognition (Linell and Thunqvist, 2003: 410). Levinson (1979: 376), for instance, states that there are activity-specific 'rules of inference' which are, in essence, the 'mirror image' of activity-specific constraints on behaviour. To clarify, he argues that the structure of a given activity type sets up certain expectations in the minds of the participants about utterance function. This in turn affects the process of inferential intention-attribution - that is, how we go about interpreting an utterance's intended meaning, as well as more generally determining 'how what one says will be 'taken' (p. 393).

Although not all genre theorists foreground cognition, Taavitsainen's (2001) frequently cited definition of genre (especially within historical pragmatics) does stress the organisation of experience:

Genres are inherently dynamic cultural schemata used to organise knowledge and experience through language (Taavitsainen, 2001: 139-140; emphasis added).

In line with this, Mayes $(2003: 21,28)$ states that much of the existing literature on genre references the 'stored knowledge' that social actors accumulate based on repeated prior experience of 'typified' (i.e., frequently repeated) activities. It is important to note, however, that (1) and (2) do not mean pragmaticians necessarily adopt a deterministic-' 'outside in' (Culpeper and Haugh, 2014: 192) view of cognitive, social, or cultural contextual resources when applying the concepts of genre or activity type. This brings us to point (3): the principle of 'act-activity co-constitution' (Linell, 1998: 237). Wittgenstein's discussion of languagegames and Levinson's activity type were both underpinned by the assumption that there is an intrinsic dialogical relationship between discourse and context (Wittgenstein, 1958: 5; Levinson, 1979: 368). In particular:

...activity types involve both what interactants do in constituting the activity and the corresponding knowledge - schemata - one has of that activity; they have an interactional and a cognitive side (Culpeper and Haugh, 2014: 192). 
According to this view, then, context is understood not as a stable aspect of the external environment, but, rather, as a dynamic process that is brought into being in and through interaction (Linell and Thunqvist, 2003: 411; see also Thomas, 1995: 189). In a similar vein, many genre theorists conceptualise genre as a) having both schematic (cognitive) and emergent (dynamic) aspects, and b) being both constituted and reconstituted by the actions of social actors (Hanks, 1996; Miller, 1984: 159; Tardy and Swales, 2014). To clarify:

...a genre is inseparable from the situation in which it occurs and is constituted by regular patterns of communicative action associated with that situation. Of course, the situation and recurring patterns of action also shape the genre (Mayes, 2003: 20).

Both activity types and genres are thus understood to be developed through interaction, socioculturally ratified, in some instances 'institutionally congealed' (Linell, 1998: 239), and then reconstructed online by participants, moment by moment.

Despite these areas of overlap, several scholars have explicitly argued that the two terms can and/or should be analytically distinguished along several dimensions (see, for example, Linell, 1998; Linell and Thunqvist, 2003; Mayes, 2003; van Eemeren, 2010, 2013). Genre and activity type are often differentiated at the level of generality, for example, such that activity types may be seen as representing specific instantiations of broader communicative genres. Consider van Eemeren's (2010: 143) pragma-dialectal book Strategic manoeuvring in argumentative discourse, in which he organises the concepts of domain, genre, activity type and speech event in descending order of specificity. Within the broad domain of legal communication, for instance, adjudication is an example of a genre. Subsumed within the latter, in turn, are the activity types of court proceedings, arbitration, and summoning. More specifically still, the 'defense pleading at O.J. Simpson's murder trial' (ibid.; emphasis original) is conceptualised as an exemplar speech event of the activity type of court proceedings. While one may disagree with the finer details of how van Eemeren conceptualises any or all of these notions, his line of argument echoes - and is echoed by - several others (Bhatia, 1993, 2004; Swales, 1990, 2004; van Eemeren and Garsson, 2013). Swales (1990: 58), for example, describes genre not as a specific communicative event but as 'a class of communicative events'. Linell (1998: 238) states that 'communicative activity types can be thought of as being organized in terms of communicative genres' (emphasis added). Linell adds further that, while genres may well be associated with particular activity types, 'there are activity types which are arguably not so culturally fixed' - such as a discussion group arranged for the express purpose of recording an interaction - and that one may thus hesitate to label these as "full-blown" communicative genres (p. 239-40). On a related note, one may differentiate between genres and activity types on the basis that the latter are explicitly described as 'bounded' (Levinson, 1979: 368; see also fn.2). Although Levinson himself does not elaborate extensively upon this aspect of his definition, he touches upon the fact that activity types are similar in many respects to speech events - that is, 'units of verbal behaviour bound in time and space' (Gumperz, 1972: 165; emphasis added). In addition, the 'paradigm examples' of activity type put forward by Levinson (1979: 368) are all bounded events, such as a job interview, a football game, or a task in a workshop. By contrast, genre - as a macro-level concept - may be conceptualised not as temporally or spatially isolable, but instead as 'continuous and intertextual' (Mayes, 2003: 34), hence the "historical" characteristic noted in Section 2.2. Genre thus shares more of an affinity with Gumperz' speech activity than with speech event (Gumperz, 1982: 166; see also Mayes, 2003; Miller, 1984). There is a sense in which activity types, in turn, may evolve over time becoming more socially, culturally, and historically embedded, leading to the formation of 'new and complex genres', according to Linell (1998: 243). 


\subsection{Activity type and genre: similarities and differences with other concepts}

As discussed in Section 2.3, both genre and activity type as concepts encompass the organisation of human experience (Culpeper and Haugh, 2014; Linell and Thunqvist, 2003). They thus share similarities with various terms used in linguistics, artificial intelligence, anthropology, and psychology to refer to cognitive 'structures of expectation' (Tannen, 1993: 21; Tannen and Wallat, 1993: 59; see also Ross, 1975), including script, schema/schemata, prototype and frame. Put simply, all of these notions are underpinned by a common principle:

...on the basis of one's experience of the world in a given culture (or combination of cultures), one organizes knowledge about the world and uses this knowledge to predict interpretations and relationships regarding new information, events, and experiences (Tannen, 1993: 16).

It is worth reiterating that Levinson (1979: 371) emphasised the central role of 'inferential schemata' in the development of (and adherence to) structural constraints on participants' 'allowable contributions' within an activity type. If we consider the words of Bartlett (1932: 201), the first psychologist to use the term schema to describe the constructive nature of human memory, we can see the similarities: 'The past operates as an organized mass rather than as a group of elements each of which retains its specific character.' In addition, what Levinson refers to as inferential schemata closely resembles a script, or a specific kind of schema(ta) that consists of:

...a structure that describes appropriate sequences of events in a particular context...Scripts handle stylised everyday situations. Thus, a script is a predetermined, stereotyped sequence of actions that defines a well-known situation (Schank and Abelson, 1997: 41).

Notice how this definition characterises scripts as involving "appropriate" sequences of events. Schema-theoretic notions, then, allow us to tap into empirical norms that contribute to politic behaviour, that is, behaviour which is 'expectable' and 'perceived to be appropriate' (i.e., 'allowable', in Levinson's terms) 'to the social constraints of the ongoing interaction' (Watts 2003: 19). Many definitions of genre within pragmatics emphasise its cognitive dimension in similar terms. Taavitsainen (2001: 139-140) explicitly references both schemata and the organisation of knowledge and experience, for example (see also section 2.3), while Włodarczyk (2016) mentions sociocognitive schemes. Drawing upon Miller's definition of genre as 'typified communicative action associated with recurrent situations' (1984: 159), Mayes (2003: 55) notes, in addition, that the genre concept demonstrates considerable areas of overlap with schema, prototype, activity type and frame. Of note, when it comes to frames in particular, is Terkourafi's (2001: 254) frame-based conceptualisation of politeness as the regular occurrence of unchallenged realizations of particular acts, allowing 'expression $x$ ' to become 'the socio-historically constrained "preferred" interpretation' for the performance of a certain act in a particular community.

According to Tannen and Wallat (1993: 59) and Mayes (2003: 28), the cognitive understanding of frame tends to capture little of the anthropological/sociological sense of frame as used/discussed by Goffman (1974, 1981) and others (see, e.g., Hymes, 1974; Gumperz, 1982). In consequence, Tannen and Wallat have drawn upon some of the extant literature as a means of making a theoretical distinction between the two understandings of this term. They use cognitive schema to encapsulate the abovementioned 'knowledge structures', and interactive 
frame to refer to 'what is going on in [a given] interaction' (1993: 59). Ultimately, however, Tannen and Wallat's (1993: 59) approach is like that of Terkourafi $(2001,2009)$, in that they tend to engage with frame analysis in ways that incorporate both understandings of the term, based on the argument that the two work together in interaction. Levinson (1979: 371) delineates the cognitive and interactive aspects of activity types on a theoretical level too, of course. Specifically, structures of expectation are referred to as inferential schemata, and are described as the 'mirror image' of structural constraints on participants' contributions. Interestingly, Mayes is amongst those genre theorists who question even the theoretical separation of cognitive schema from interactive frames:

Is human knowledge actually divided in this way - one part devoted to cognitive processes and one part to social interaction? [...] I suggest that a more natural approach would be to merge these two concepts, despite the fact that they have been dealt with separately in the literature (Mayes, 2003: 35).

The dichotomy drawn between cognition and social interaction seems, at least in part, to reflect conventions within a given (sub-)discipline, and/or researchers' predominant goals. For instance, Culpeper and McIntrye (2010: 178) note that many researchers within pragmatics who have applied the concept of activity type have paid less attention to the cognitive element than to the 'pragmatic interactional' element (p. 204). Whether or not cognition and social interaction are dealt with separately on a theoretical level, genre and activity type (as well as the broader notion of frame encapsulated in the work of, e.g., Tannen, Terkourafi, Wallat, etc.) are all equipped to deal with both at the analysis level.

\section{Critical overview of two case studies}

\subsection{Culpeper and McIntyre (2010)}

Culpeper and McIntyre's (2010) paper begins by providing a comprehensive theoretical background of the activity type concept. The authors are particularly careful, here, to highlight the (often-overlooked) cognitive dimension of activity types, emphasising that the notion encapsulates 'both what interactants do in constituting the activity and the corresponding knowledge one has of that activity' (p. 178). As discussed in 2.2, then, act-activity coconstitution is a central component of the activity type concept: language use both shapes and is shaped by context, rather than simply statically reflecting it (ibid.). This aspect is emphasised by the authors throughout their paper, with a view to redressing the analytic im/balance between the traditional outside-in approach to context in pragmatics (cf. Huang 2014: 17) and the inside-out, dynamic approach which assumes that language is context-creating (i.e., shapes/produces context in situ). In doing so, they manage to provide an extensive theoretical supplement to Levinson's original ([1979] 1992) explication.

The cognitive aspect captured by the notion of activity types equates to the 'strong expectations about the functions' utterances will fulfil (Levinson, 1992: 79) at certain points in an exchange. Elsewhere, Levinson (1992: 72, 97) describes these expectations as the 'set of inferential schemata' that participants draw upon in order to evaluate what is said in activity-typeappropriate ways (Levinson, 1992: 72, 97; emphasis original). Consider How are you? In most circumstances, this would function as a phatic question. In a clearly demarcated activity such as a doctor-patient consultation, however, patients are likely to use their knowledge-based 
schematic inferencing and conclude that the doctor wants them to provide him or her with an assessment of their physical health and/or mental wellbeing.

It is worth reiterating the overlap with schema theory here (see especially Section 2.4), given Culpeper and McIntyre (2010: 179) mention that Schank and Abelson's (1977) script-based approach to schema theory has 'some particular affinities with activity types'. Succinctly put, '[s]chemata enable us to construct an interpretation that contains more than the information we receive from the text. We can supply, or infer, extra bits of information from our schematic knowledge' (Culpeper and McIntyre 2010: 179). The activation of a particular schema triggers speaker's expectations. Following Neisser (1976: 22), the authors define schemata as anticipations that mediate between past and present experiences. For the purposes of their study, they then operationalise Schank's and Abelson's (1977) and Schank's $(1982,1999)$ notion of script and scene respectively. Scripts are proposed to work at a more specific level of knowledge structures and, thus, determine speakers' expectations within a given activity, whereas scenes are said to operate at a more general level. Scenes, then, are more affiliated with the setting and participants' goals, whereas scripts 'are more focused on just the actions or one set of possible actions within the scene' (Culpeper and McIntyre 2010: 180).

The authors demonstrate how the schematic aspect of activity types can be operationalised at the level of analysis by applying it to dramatic texts. Specifically, they focus upon four extracts drawn from two screenplays: a job interview from Danny Boyle's Trainspotting, and a police interview from BBC's One Foot in the Grave. They are careful to point out that their analysis is not, technically speaking, an analysis of a job interview activity type, but an analysis of interview scenes or scripts (p. 180). They go on to demonstrate, nonetheless, that particular characterisations can be 'foregrounded as a result of deviation[s] from what is expected' ( $\mathrm{p}$. 204). Consider the following example from the fictional job interview in Trainspotting:

Man $1 \quad$ Mr Murphy, do you mean that you lied on your application?

Spud Only to get my foot in the door. Showing initiative, right?

The authors note, here, that Spud pragmatically deviates from a prototypical interview response by openly admitting to having lied on his application form. The effect of Spud's nonconformance to the interview activity type is to characterise him as 'overly confident', 'unaware of social conventions', 'inattentive', and 'unintelligent' (p. 194-5). Thus, the 'schematic aspect of activity types' (p. 187) helps to explain how we make particular inferences about a character, about that character's social role, and about 'oddities of character' (p. 204).

In addition to their detailed explication of the cognitive dimension of the notion of activity type the authors summarise the more familiar, and more widely explored, interactional dimension, which boils down to how participants interactionally constitute activity types. They refer, in this case, to Thomas' (1995: 190-192) comprehensive list of elements, which are designed to elaborate on what Levinson labelled 'allowable contributions' (such as participants' goals and their allowable contributions). The authors characterise the comprehensiveness of the list as a double-edged sword; that is, they may help to capture the specific nature of some activity types, but may also obscure the differences between them (p. 182). Here, the authors incorporate Sarangi's (2000) notion of discourse type, which helps to characterise 'the forms of talk occurring within activity types' (Culpeper and McIntyre, 2010: 182). The main difference between the notion of discourse type and that of an activity type centres around the fact that the latter concentrates predominantly on contextual factors, whereas the former focuses on the forms of talk which may include, for example, history taking and promotional talk (cf. Sarangi 
2000: 3). Culpeper and McIntyre make clear that their focus is upon such 'forms of talk' in their dramatic texts. They begin by establishing the typical features of the interview (drawing heavily on the work of Button, 1992). This includes explaining the linguistic structures of the interview activity type, following what Button (1992) labels 'interview orthodoxy', that is, 'the elements that we might expect to see in all variations of the interview activity type' (Culpeper and McIntyre 2010: 184). Button's elements are, broadly speaking, 'conversation-analytic sequential practices' and 'conventionalisation conventions' (ibid.). For example, one has to do with there being no provision for interviewee's answers that extend over several turns, or the fact that the interviewee's first answer is taken to be complete and that no corrections are (typically) allowed. Culpeper and McIntyre then go on to supplement Button's list with 'other types of knowledge which feed into the job interview schema' in the British cultural context, such as assumptions about the dress code or the appropriate register (p. 185).

The authors operationalise the interactional component of the activity type concept as a means of demonstrating how it might be applied to the analysis of characterisation in dramatic discourse. Consider the following extract, taken from Culpeper and McIntyre (p. 189):

Man 2 You seem eminently suited to this post but I wonder if you could explain the gaps in your employment record?

Renton Yes I can. The truth - well, the truth is that I've had a long-standing problem with heroin addiction. I've been known to sniff it, smoke it, swallow it, stick it up my arse and inject it into my veins. I've been trying to combat this addiction, but unless you count social security scams and shoplifting, I haven't had a regular job in years. I feel it's important to mention this.

Culpeper and McIntyre highlight that, while the register adopted by Renton remains rather formal and thus appropriate to the interview activity type, his use of taboo language - coupled with his frank admission of heroin addiction and criminal activity - conflicts sharply with the overarching goal of the job interview as an activity type (that is, to secure the job). Prior to this extract, Renton had presented himself as highly educated through his 'relatively sophisticated register' (p.190) and had developed a rapport with one of the interviewers as a result. At this point, however, he sharply subverts this characterisation through his (inappropriate) linguistic choices. In this way, Culpeper and McIntyre demonstrate that 'a major source of humour in the extract is...Renton's linguistic construction of the interview' (p. 191; emphasis added).

When discussing these and similar extracts, Culpeper and McIntyre are careful to emphasise and draw upon the dual-aspect of the activity type concept, with the purpose of demonstrating that both the cognitive and (pragmatic) interactional dimensions are relevant to the stylistic analysis of dramatic texts. As they note, adopting a dual-aspect activity type approach in this way can capture particular dramatic effects (such as humour and irony), as well as 'feed into both bottom-up and top-down processes of characterisation' (p. 204). It thus offers promise as a more "holistic" analysis of drama as discourse. The authors also go on to acknowledge, however, that the interview as an activity type is 'relatively conventionalised and stable, and thus relatively easy to describe' (p. 205). For this reason, the application of an activity type approach may not prove quite so "neat" on a less clearly demarcated activity type, and/or to data taken from real-life interaction (see also Section 4).

\subsection{Tardy and Swales (2014)}


As noted in Section 2.2, Tardy and Swales (2014) provide a useful explanation in respect to how - in spite of a previous focus on spoken versus written interaction respectively - genre analysis and pragmatics have nonetheless moved closer together since the 1980s. For instance, they note that genre analysts have become increasingly interested in spoken genres over the course of the past two decades and that, correspondingly, pragmatists have begun to show interest in written texts. They further note that genre is now considered to be an important analytical tool in examining the pragmatics of both spoken and written discourse (ibid.). On a theoretical level, the authors explain that genres - like activity types - 'both shape and are shaped by the communities and contexts in which they exist' (p. 196). Following Miller (1984), they also see genres as being socially situated, dynamic categories of discourse which are formed in order to carry out social actions and purposes (see also Swales, 1990). They are understood, however, to be intertextually linked to one another rather than isolable, and note that power dynamics are embedded within genres, since they are 'reflections of the social groups that use them'.

On a more practical note, Tardy and Swales (2014: 198-206) outline the repertoire of methods that make up genre analysis. They include: text analysis (supported by corpus-based analysis), move structure analysis, comparative genre analysis (comparing linguistic, national, professional or disciplinary affiliations), diachronic genre analysis, genre system analysis (focused on genres as clusters or networks), critical genre analysis, multimodal/visual genre analysis and the study of genre and identity (see also Barron and Schneider, 2014: 11). A commonality among these methods is the goal of 'gaining insight into the social function of language' (Tardy and Swales, 2014: 198). With this in mind, it is not uncommon to adopt a mixed-method approach (as part of genre analysis) that examines multimodal data, from spoken language and written texts to graphical, figurative, and numerical data (p. 204). While the concept of genre has traditionally been applied to 'communities of texts' (Tardy and Swales, 2014: 205), the authors note that there has also been recent interest in examining the ways in which individuals assert their identity within a given text by, for instance, subverting genre conventions (see, for example, Hyon, 2008; Hyland, 2008; Matsuda and Tardy, 2007).

The authors go on to apply a selection of the abovementioned methods to sixty bio-statements from two linguistics journals, i.e. Applied Linguistics (henceforth AL) and the ELT Journal (henceforth ELTJ), as a means of demonstrating what kinds of insights we might gain from each (as well as collectively). Their focus upon biographical notes is due to these texts' tendency to serve two important purposes, in spite of their relatively short length (around ninety words). That is, they provide relevant background information about the author/researcher whilst establishing their (academic) credibility, identity and ethos. Tardy and Swales (2014) start by analysing textual features: in particular, they provide frequencies of the most commonly used content words in the two samples. They found, for example, that the authors' bionotes prepared for ELTJ included the word research more frequently than is the case with AL. Tardy and Swales (2014: 208-9) suggest this may reflect the contributors' greater interest in conducting academic research than is the case with the ELTJ, which is aimed primarily at teachers and ELT practitioners. In addition, the authors argue that the high frequency of the nouns university, language, and education likely reflect 'the importance attached to institutional affiliation and degree names' (p. 208).

They also point to the different ways in which the contributors to both journals refer to themselves (i.e. formal titles as opposed to their first names) in the analysed notes, which might be taken to reflect how firmly they are embedded in their (hierarchical) academic culture. For instance, while the first person pronoun $I$ does not appear in the bio-notes of either journal, two 
Anglo male authors refer to themselves by their title (Professor), while two Anglo female ELTJ authors refer to themselves by their first name only. Consistent with this, the few examples of evaluative adjectives and adverbs that appear in AL only are used to emphasize scholarly strength:

... he is also well known for his research into teaching and learning ... Professor [Name] is a prolific writer and he has published twelve books ...

Tardy and Swales (2014) go on to analyse the rhetorical moves carried out by the authors of the bio-notes. They identify six types of moves, designed to either describe position or mention publications composed altogether of fourteen steps. This includes the following:

1. Describing one's professional role/position

2. Establishing formal qualifications

3. Mentioning publications

4. Describing research areas

5. Describing professional activities

6. Describing honours

(adapted from pg. 211)

Tardy and Swales suggest that the journals' contributors use these rhetorical moves 'in order to build their credibility as a published writer, illustrating their credentials as well as their experiences that they hope are valued in the field' (Tardy and Swales 2014: 213). While the authors note that there is a high degree of similarity between the AL and ELTJ corpora, they point to several discrepancies between the samples in terms of incorporating all the possible moves. To illustrate: within the AL bio-statements, $90 \%$ of statements incorporate move 4 (describing research areas), compared to only $60 \%$ of ELTJ statements. Tardy and Swales (2014) argue that, once again, this reflects AL's focus on research as opposed to classroom practice. By contrast, $70 \%$ of authors within the ELTJ bio-statements included move 5 (describing professional activities), compared with 50\% of those from AL. This places a greater emphasis on the value of being 'an active practitioner' (ibid.).

The authors' third stage of analysis involves exploring identity in some detail. Here, Tardy and Swales (2014: 215) highlight how, in spite of the specific rhetorical context, the journal contributors' still exercise freedom when negotiating their self-presentations. ELTJ is, according to Tardy and Swales, more flexible here than AL, perhaps because there is more scope for emphasising 'a teaching persona' as well as a publishing or research persona. With regard to ELTJ, this was achieved by some authors through foregrounding their practical ELT experience over and above any research expertise (p. 215).

The authors' final piece of analysis adopts a more 'critical' approach (p. 216). This kind of genre analysis concerns itself with the very nature of the genre of bio-notes, which privileges or foregrounds certain aspects of (academic) identity that are assigned certain symbolic value(s) or that may have varying symbolic capital. Needless to say, not all of these identity aspects are equally available to all journals, thereby demonstrating how 'power dynamics are embedded in genres' (Tardy and Swales 2014: 216). For example, move 1 (describing one's position) is noted as 'near-obligatory' (p. 216) in both AL and ELTJ, though they may place differing levels of emphasis on positions versus institutional affiliations. In AL, for instance, positions like "professor", "director", or "senior lecturer" afford more prestige than "doctoral student" or "senior lecturer". In light of this, Tardy and Swales (2014) argue that certain aspects 
of professional identity are 'privileged' within these bio-statements, which 'reproduces the power structure that lends prestige to these characteristics' (ibid.).

The authors conclude their sample analysis by emphasising that the presented methodological approaches 'shed light on different generic patterns and features, giving the genre analyst a repertoire of complementary tools from which to choose' (Tardy and Swales 2014: 217). The theoretical portion of this paper is afforded less prominence than its methodological counterpart; the authors provide only a brief ostensive definition of genre based upon previously established key features of genre in the extant literature, such as its socially situated character, the concept of rhetorical action and intertextuality (see also Bakhtin, 1986; Miller, 1984). Such a focus is understandable and likely deliberate, given that this paper was written for the series Handbooks of Pragmatics. Its practical slant is therefore particularly useful for any pragmatician wishing to embark upon genre analysis.

\section{Summary and future directions}

This chapter has critically compared the concepts of activity type and genre with regard to both their historical and (sub-)disciplinary origins, and subsequent uses in various disciplines - but especially pragmatics - as a means of assessing their similarities and differences with regard to (i) each other and (ii) concepts that share 'a considerable family resemblance' (Linell, 2010: 42) to them. In the process, it has become clear that activity type tends to be the more popular concept of the two within the field of general pragmatics, even though there are signs that the genre concept is growing in use (see 3.2). There have also been attempts to combine the two, as part of a specificity scale that also includes domain and speech event (van Eemeren 2010: 143; see also 2.3). Within this scale, it is suggested that genres are made up of activity types or what Swales (1990: 58) likes to call 'communicative events', and that activity types are made up of speech events (cf. Levinson's 1979: 368 description of social events). This is in line with Mayes' (2003: 34) understanding of genre as a 'continuous and intertextual' macro-level concept (cf. Gumperz' 1982: 166 notion of speech activity). Activity types and speech events, in contrast, share the characteristic of being 'bound in time and space' (Gumperz 1972: 165; Levinson 1979: 368). This does not prevent activity types evolving over time, however, such that they become more socially, culturally and historically embedded. As they do so, Linell (1998: 243) believes they may form 'new and complex genres', which we might want to explain as moving to a different point of the specificity scale.

A related characteristic that both concepts share is their "fuzzy" nature. Indeed, Levinson (1979: 368) in particular emphasised that the boundaries of an activity type need not be clearly demarcated at all, adding further that activity types will tend to sit 'along a gradient formed by two polar types', namely, 'the totally pre-packaged activity on the one hand... and the largely unscripted event on the other'. Such fuzziness can be useful, of course, especially when our interest lies in differentiating the less prototypical members of a given activity type (or genre) from its more prototypical members (Mayes 2003: 33), as well as differentiating one activity type (or genre) from another. As Mooney (2004: 905) and LoCastro (2013: 66) both note, in identifying a given activity type - say, courtroom cross-examination or classroom - we provide ourselves with useful information with regard to situational constraints, and hence related expectations regarding who, what, when and how co-participants might be expected to contribute to the unfolding interaction. It is this aspect of the activity type concept, in particular, that leads Mooney (2004: 905) to argue for its ability to give greater explanatory power to concepts like the Cooperative Principle (Grice, 1975), not least because 
Using activity types forces the analyst to reconsider the goals of [such] discourse activities...[as it is not $\mathrm{u}$ ]ntil one knows the "structural properties of an activity" that one can [suitably] understand the way in which these properties "constrain... the verbal contributions that are made (Levinson 1979: 370)" (italics as in original).

As Culpeper and McIntyre (2010: 178) note, Levinson was very much aware of 'the strict constraints on contributions' with regard to a 'particular activity' and how they can lead, in turn, to 'corresponding strong expectations about the functions that...utterances...can be fulfilling' within a given activity type. Hence, his theoretical delineation of inferential schemata from structural (i.e., interactional) constraints, drawing on the metaphor of a 'mirror image' (Levinson 1979: 371). As highlighted in Section 2.4, this cognitive-interactional dynamic is evident in the genre concept too. For example, genres are often argued to overlap with and/or are explained with reference to other cognitive-based concepts such as schema(ta), prototype and frame (Mayes, 2003: 55). Some researchers - such as Tannen and Wallat (1993: 59) - have even sought to draw on some of the latter to delineate 'knowledge structure' (i.e., cognitive schema) from 'what is going on in [a given] interaction' (i.e., interactive frame). Mayes (2003: 35), in contrast, has argued for a merging of the 'two concepts, despite the fact that they have been dealt with separately in the [extant] literature'.

One reason they may have been dealt with separately relates to the conventions within a given (sub-)discipline. A second related reason relates to researchers' predominant goals. For example, the cognitive aspect of activity types (or genres) has received much less attention than the interactional aspect within the field of general pragmatics (be it by Levinson or others). The bias towards the interactional may be due, in part, to the well-known concern that what 'is in people's heads is accessible neither to analysts nor to interlocutors (nor even...to those whose behaviour is under investigation)' (Grimshaw 1990: 281). 'Rather, we are all reliant on assessing plausible intentions, using the evidence available to us' (Archer 2017: 392). This is less problematic if researchers use fictional texts as their data sources, as Culpeper and McIntyre (2010) do, as the authors of such works can provide us with insights into their characters' innermost thoughts. We would contend, nonetheless, that both activity type and genre have been developed and operationalised in ways that allow future researchers to begin analysing the complex interplay between multiple dimensions of real-life data: that is, language, social structure, culture, cognition, etc. It might be necessary, however, for those researchers to traverse beyond their (sub-)disciplinary boundaries, so that they might together account for the complexities of interaction and, in particular, any representativeness of a specific activity type and genre.

\section{References}

Allwood, J. (2000). An activity based approach to pragmatics. In H. Blunt and W. Black, eds., Abduction, belief and context in dialogue: Studies in computational pragmatics. Ambsterdam and Philadelphia: John Benjamins, pp. 47-80.

Allwood, J. (1976). Linguistic communication as action and cooperation, Gothenburg Manuscripts in Linguistics 2. Göteburg.

Archer, D. (2017). Politeness. In A. Baron, Y. Gu, and G. Steen, eds., The Routledge Handbook of Pragmatics. London and New York: Routledge, pp. 384-398.

Barron, A. \& Schneider, K. P. (2014). Discourse pragmatics: signposting a vast field. In K. P. Schnieder and A. Barron, eds., Pragmatics of Discourse. Berlin/Boston: Mouton de Gruyter, pp. 1-33. 
Barlett, F. C. (1932). Remembering: A Study in Experimental and Social Psychology. Cambridge: Cambridge University Press.

Bawarshi, A. S. and Reiff, M. J. (2010). An Introduction to History, Theory, Research and Pedagogy. West Lafayette, Indiana: Parlor Press LLC.

Bazerman, C. (1997). The life of genre, the life of the classroom. In W. Bishop and H. Ostrom, eds., Genre and Writing. Portsmouth, NH: Boynton/Cook-Heinemann, pp. 19-26.

Belton, R.J. (1996). The Elements of Art. Art History: A Preliminary Handbook. https://www.academia.edu/23437708/Art_History_A_Preliminary_Handbook_1996

Bhatia, V.K. (1993). Analyzing Genre: Language Use in Professional Settings. New York: Longman.

Bhatia, V.K. (2008). Towards critical genre analysis. In: V. K. Bhatia, J. Flowerdew and R. H. Jones, eds., Advances in Discourse Studies. London and New York: Routledge, pp. 166-177.

Biber, D. (1988). Variation Across Speech and Writing. Cambridge: Cambridge University Press.

Claridge, C. (2012). Styles, registers, genres, text types. In A.T. Bergs and L.J. Brinton, eds., English historical linguistics: An international handbook. Berlin: Mouton de Gruyter, pp. 237-253.

Clark, H.H. (1996). Using Language. Cambridge: Cambridge University Press.

Culpeper, J. and Haugh, M. (2014). Pragmatics and the English Language. Hampshire: Palgrave Macmillan.

Culpeper, J., and MacIntyre, D. (2010). Activity Types and Characterisation in Dramatic Discourse. In J. Eder, F. Jannidis and R. Schneider, eds., Characters in Fictional Worlds: Understanding Imaginary Beings in Literature, Film, and Other Media. Berlin/New York: Walter de Gruyter, pp. 176-207.

Eemeren, F.H. van (2010). Strategic maneuvering in argumentative discourse: Extending the pragmadialectical theory of argumentation. Amsterdam: John Benjamins Publishing Company.

Eemeren, F.H. van \& Garssen, B. (2013). Argumentative patterns in discourse. In D. Mohammed and M. Lewiński, eds., Virtues of Argumentation: Proceedings of the $10^{\text {th }}$ International Conference of the Ontario Society for the Study of Argumentation (OSSA), 22-26 May 2013. Windsor, ON: OSSA, pp. 1-15.

Forgas, J.P. (1979). Social Episodes: The Study of Interaction Routines. London, New York: Academic Press.

Goffman, E. (1981). Forms of Talk. Philadelphia: University of Pennsylvania Press.

Grice, H.P. (1975). Logic and conversation. In P. Cole, ed., Syntax and Semantics 3: Speech Acts. New York: Academic Press, pp. 41-58.

Grimshaw, A.D. (1990). Research on conflict talk: Antecedents, resources, findings, directions. In A.D. Grimshaw, ed., Conflict Talk: Sociolinguistic Investigations of Arguments and Conversations. Cambridge: Cambridge University Press, pp. 281-324.

Gumperz, E. (1972). Introduction. In J. Gumperz and D. Hymes, eds., Directions in Sociolinguistics. New York: Holt, Rinehart and Winston, pp. 1-26.

Gumperz, J. (1982). Discourse Strategies. Cambridge: Cambridge University Press. Hanks, W.F. (1996). Language and Communicative Practices. Boulder, CO: Westview Press. Hoey, M. (2001). Textual interaction: An introduction to written discourse analysis. London: Routledge.

Hymes, D. (1962). The ethnography of speaking. In: T. Gladwin and W. Sturtevant, eds., Anthropology and Human Behavior. Washington, DC: Anthropological Society of Washington, p. 13-53. 
Lee, D.Y.W. (2001). Genres, registers text types, domains, and styles: Clarifying the concepts and navigating a path through the BNC jungle. Language Learning \& Technology, 5(3): 37-72.

Levinson, S. (1992). Activity types and language. In P. Drew and J. Heritage, eds., Talk At Work. Mouton: The Hague, pp. 66-100.

Levinson, S. (1979). Activity types and language. Linguistics 17: 365-399.

Linell, P. (1998). Approaching Dialogue: Talk, interaction and contexts in dialogical perspectives. Amsterdam: John Benjamins Publishing Company.

Linell, P. and Thunqvist, D.P. (2003). Moving in and out of framings: activity contexts in talks with young unemployed people within a training project. Journal of Pragmatics, 35: 409-434.

LoCastro, V. (2013). Pragmatics for Language Educators: A Sociolinguistic Perspective. New York and London: Routledge.

Luckmann, T. (1992). On the communicative adjustment of perspectives, dialogue and communicative genres. In A.H. Wold, ed., The Dialogical Alternative. Oslo: Scandinavian University Press, pp. 219-234.

Martin, J.R. (1984). Language, register \& genre. In F. Christie, ed., Children Writing: Reader. Geelong, Vic: Deakin University Press, pp. 21-30.

Martin, J.R. (1985). Process and text: Two aspects of semiosis. In J.D. Benson and W.S. Greaves, eds., Systemic Perspectives on Discourse, Vol. 1: selected theoretical papers from the $9^{\text {th }}$ International Systemic Workshop. Norwood, NJ: Ablex, pp. 248-74.

Mayes, P. (2003). Language, Social Structure, and Culture: A genre analysis of cooking classes in Japan and America. Amsterdam: John Benajmins.

Miller, C.R. (1984). Genres as social action. Quarterly Journal of Speech 70: 151-167.

Mooney, A. (2004). Co-operation, violations and making sense. Journal of Pragmatics 36: 899-920.

Paltridge, B. (1997). Genre, Frames and Writing in Research Settings. Amsterdam and Philadelphia: John Benjamins.

Ross, R.N. (1975). Ellipsis and the structure of expectation. San Jose State Occupational Papers in Linguistics 1: 183-191.

Sarangi, S. (2000). Activity types, Discourse types and Interactional Hybridity: The Case of Genetic Counselling. In S. Sarangi and M. Coulthard, eds., Discourse and Social Life. London: Pearson Education Ltd, pp. 1-27.

Schank, R.C., and Abelson, R.P. (1977). Scripts, Plans, Goals and Understanding: An Inquiry into Human Knowledge Structures. Hillsdale, NJ: Lawrence Erlbaum Associates.

Swales, J.M. (1990) Genre Analysis: English in Academic and Research Settings. Cambridge: Cambridge University Press.

Taavitsainen, I. (2001). Changing conventions of writing: The dynamics of genres, text types, and text traditions. In L. Moessner (Ed.), Early Modern English text types. Special issue of European Journal of English Studies, 5(2): 139-150.

Tannen, D. (1993). Framing in Discourse. Oxford: Oxford University Press.

Tannen, D. \& Wallat, C. (1993). Interactive frames and knowledge schemas in interaction: examples from a medical examination/interview. In D. Tannen, ed., Framing in Discourse. Oxford: Oxford University Press, pp. 57-76.

Tardy, C.M. \& Swales, J.M. (2014). Genre analysis. In K.P. Schneider and A. Barron, eds., Pragmatics of Discourse. Berlin/Boston: Mouton de Gruyter, pp. 165-188.

Terkourafi M. (2009), On de-limiting context. In A. Bergs and G. Diewald, eds., Context and Constructions. Constructional Approaches to Language no. 9 Amsterdam: John Benjamins Publishing Company. 17-42. 
Terkourafi, M. (2001). Politeness in Cypriot Greek: A Frame-based Approach. Cambridge: Cambridge University Press.

Thomas, J. (1995). Meaning in interaction: An Introduction to Pragmatics. London: Longman.

van der Merwe, P. (1989). Origins of the Popular Style: The Antecedents of TwentiethCentury Popular Music. Oxford: Clarendon Press.

Wittgenstein, L. (1958). Philosophical Investigations. Translation by G.E.M. Ansycombe. Second Edition. Oxford.

Włodarczyk, M. (2016). Genre and literacies: Historical (socio)pragmatics of the 1820 settler petition. Poznań: Adam Mickiewicz University Press. 